\title{
AUDIBLE AND INFRASONIC NOISE LEVELS IN THE CABINS OF MODERN AGRICULTURAL TRACTORS - DOES THE RISK OF ADVERSE, EXPOSURE-DEPENDENT EFFECTS STILL EXIST?
}

\author{
BARTOSZ BILSKI \\ Poznan University of Medical Sciences, Poznań, Poland \\ Department of Preventive Medicine
}

\begin{abstract}
Introduction: The agricultural tractor is one of the most commonly used vehicles on farms and one of the most prominent sources of noise. This article presents an exemplary assessment of the audible and infrasonic noise levels in the cabins of selected modern wheeled agricultural tractors. Materials and Methods: Operator-perceived audible and infrasonic noise levels in the cabins were examined for 20 types of modern tractors during typical conditions of work. The tractors had been in use for no longer than 3 years, with rated power between $96 \mathrm{~kW}$ and $227 \mathrm{~kW}$, designed and produced by world-renowned companies. Noise level measurements were performed in accordance with PN-EN ISO 9612:2011 (ISO 9612:2009). Results: Audible noise levels (A-weighted) ranged from 62.1 to $87.4 \mathrm{~dB}-\mathrm{A}$ (average: 68.2 to $83.8 \mathrm{~dB}-\mathrm{A}$ ) for different work tasks. The factors influencing noise levels include performed tasks, soil, weather conditions and the skills of individual drivers. In spectrum analysis, the highest noise levels occurred at frequencies $250 \mathrm{~Hz}, 1$ and $2 \mathrm{kHz}$. Infrasound noise levels (G-weighted) ranged from 87.3 to $111.3 \mathrm{~dB}-\mathrm{G}$. The driver-experienced exposure to infrasound was found to increase significantly when the vehicle was in motion. Conclusions: Average audible noise levels have no potential to adversely affect the hearing organ during tasks performed inside the closed cabins of the analysed modern agricultural tractors. Due to the relatively low audible noise levels inside the cabins of modern agricultural tractors, non-auditory effects are the only adverse symptoms that can develop. Modern agricultural tractors emit considerable infrasonic noise levels. All tractors introduced into the market should be subjected to tests with regard to infrasonic noise levels.
\end{abstract}

Key words:

Tractors, Operators, Noise, Infrasound

\section{INTRODUCTION}

Noise is a significant hazard in the working environment of the agricultural sector. Individual farm owners and workers employed on large farms are typically exposed to noise from many sources (tractors, farming machines joined to tractors, self-propelled farming machinery and stationary farming machines). The agricultural tractor is one of the most commonly used vehicles on farms. In recent years, the driver-perceived audible noise levels have been reduced due to considerable technical progress. However, according to the relevant data published so far, this phenomenon only rarely has been addressed. According to a number of studies of old-generation agricultural tractors, the noise generated by these vehicles significantly exceeded daily or

Received: December 20, 2011. Accepted: January 28, 2013.

This paper was performed in scientific cooperation with Dezydery Chłapowski - Research Institute in Działyń (Poland).

Corresponding author: B. Bilski, Department of Preventive Medicine, Poznan University of Medical Sciences, Smoluchowskiego 11, 60-179 Poznań, Poland (e-mail: bilski@ump.edu.pl). 
weekly limits of noise exposure and caused noise-induced hearing loss. Solecki, for example, reported that the average daily $(8 \mathrm{~h})$ exposure level to audible noise $\left(\mathrm{L}_{\text {eq,8h }}\right)$ in the driver's seat of medium size tractors exceeded Polish Occupational Exposure Limits [1]. The financial standing of farmers in the countries that have recently become Member States of European Union has improved significantly, and a large share of old-generation machines have been replaced with modern equipment, which has resulted in considerable progress in decreasing exposure to audible noise among the drivers of agricultural tractors. The levels of audible noise generated by the tractor engine and its components have been reduced ("active methods"), while ergonomic cabin structures have further decreased the driver's exposure ("passive methods") [2,3]. Paradoxically, the noise levels in the driver's cabin are typically lower than those outside (according to the measurement method set out in the European Union Directive) [4].

The fact that the noise levels generated by engines vary considerably between individual vehicles depending on various factors, including engine components and the type of work being done, is also noteworthy. In addition, high fluctuations in the noise level can be identified depending on the specific type of work in progress, driver's skills, soil and weather conditions, different engine loads as well as vehicle speed. It is worth remembering that driving a tractor is associated with accompanying whole-body vibration (in old-generation tractors) which in synergistic influence with noise, can lead to damage to the vestibulocochlear organ [5-9].

Moreover, agricultural tractors are an important source of infrasound noise. Infrasound consists of acoustic oscillations, the frequency of which is below the low frequency limit of audible sound (about 16-20 Hz) [10]. According to the Polish Standard PN-Z-01338:2010, infrasound is defined as a frequency spectrum between 1 and $20 \mathrm{~Hz}$ [11]. Exposure to this hazard generated by wheeled agricultural tractors and different wheeled vehicles has already been examined [12]. However, there are no broad-scale analyses covering technological progress in engine design which could contribute to the reduction of exposure to infrasound. This paper presents the assessment of audible and infrasonic noise pressure levels in the cabins of selected modern agricultural tractors the possible consequences of such exposure.

\section{MATERIALS AND METHODS}

Noise levels were examined for 20 types of modern cab-type tractors during normal conditions of work. The examined tractors have been in use for no longer than 3 years, with rated power between $96 \mathrm{~kW}$ and $227 \mathrm{~kW}$ (as per $97 / 68 \mathrm{EC}$ ), designed and produced by world-renowned companies (John Deere - 8 tractors, Case- 8 , New Holland and Fend - 2 tractors). Noise level measurements were performed in accordance with PNEN ISO 9612:2011 and ISO 9612:2009 [13,14]. These standards determine the procedure of the analysis of occupational exposure to noise in five steps: analysis of working conditions, selection of measurement strategy, measurements, analysis of errors and uncertainty of measurements as well as calculation and presentation of the results, including the uncertainty of measurement. This analysis omitted exposure to noise according to the length of working day or week $\left(\mathrm{L}_{\text {eq, } 8 \mathrm{~h}}\right.$ or $\left.\mathrm{L}_{\text {eq,week }}\right)$ as it depended on both exposure to noise and its duration. The author decided to assess the noise levels in cabins generated by selected modern tractors, instead of analysing farm-specific exposure to noise. Exposure to noise level is defined as driver-experienced noise levels and the duration of exposure. The results include the most important parameters: audible and infrasonic noise time averaged levels in the cabins of selected tractors $\left(\mathrm{L}_{\text {Aeq,Te }}, \mathrm{L}_{\text {Geq,Te }}\right)$. Measurement uncertainty was assessed according to the Annex C of the PNEN ISO 9612:2011 (ISO 9612:2009) standards, assuming that exposure to noise during a particular task was identical during the 8-hour working day to the exposure during the time of measurement Te, which is $\mathrm{L}_{\text {Aeq,8h }}=\mathrm{L}_{\text {Aeq,Te }}$. 
Measurements were performed in in accordance with EN ISO/IEC 17025:2005 and in cooperation with a laboratory for noise measurements accredited by the Polish Centre for Accreditation: a signatory to the International Laboratory Accreditation Cooperation (ILAC MRA) and the European Co-operation for Accreditation (EA MLA) [15]. Measurements were taken with the use of a DSA-50 digital sound analyser (class 1 instrument), by SONOPAN and a KA-50 acoustic calibrator (class 1 instrument) by SONOPAN. All measuring instruments had calibration certificates. The parameters set in DSA-50 sound level meter were as follows: basic error for sinusoidal signal $(1 \mathrm{kHz})$ : up to $\pm 0.7 \mathrm{~dB}$; influence of temperature: up to $\pm 0.5 \mathrm{~dB}$; influence of humidity: up to $\pm 0.1 \mathrm{~dB}$; influence of atmospheric pressure: $-0.01 \mathrm{~dB}$ / $\mathrm{kPa}$ (for $1 \mathrm{kHz}$ ); influence of electromagnetic/electrostatic fields: consistent with EN 61672-1 [16]. All measurements of noise were taken in the cabins with closed windows the study included only tractors with air conditioning and a cabin structure. Open windows significantly affect the levels of audible and infrasonic noise [12,17]. Apart from exposure to noise using A, C and G filters, measurements of the octave band spectrum emitted by tractors were carried out [18].

\section{RESULTS}

The presented analysis includes task-specific driver-experienced audible and infrasonic noise levels. The tasks (performed in closed cabins) were as follows (Figure 1 and 2):

- preparation of tractors and accompanying equipment for operation - tractor setting and start-up,

- application of the Power Take-Off (PTO) shaft when the tractor is at a standstill - mixing feed using a feed mixer/distributor,

- access and transport to the fields using hard-surfaced roads,

- ploughing.

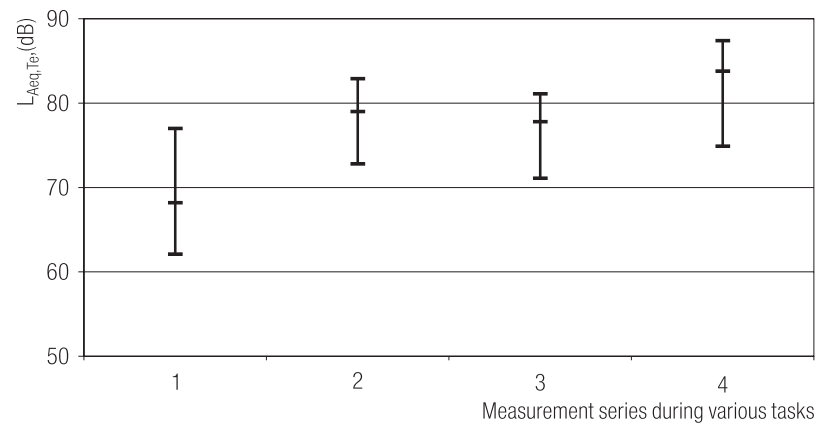

1 - preparation of tractors and accompanying equipment for operation - tractor setting and start-up.

2 - ploughing.

3 - access and transport to the fields using hard-surfaced roads.

4 - application of Power Take-Off (PTO) shaft when the tractor is at a standstill - mixing feed using a feed mixer/distributor.

The measurements were performed according to PN-EN 9612:2011 and EN ISO 9612:2009 standards (3 series of measurements, measurement time Te min. $5 \mathrm{~min}$.). Maximum uncertainty of measurement series of noise exposure for each analysed tractor does not exceed 2,8 dB (assuming the same level in 8-hour-duration of each of the above - mentioned tasks) [13].

Fig. 1. Task-specific audible noise time averaged levels $\left(\mathrm{L}_{\text {Aeq,Te }}\right)$ in the cabins of 20 selected modern tractors

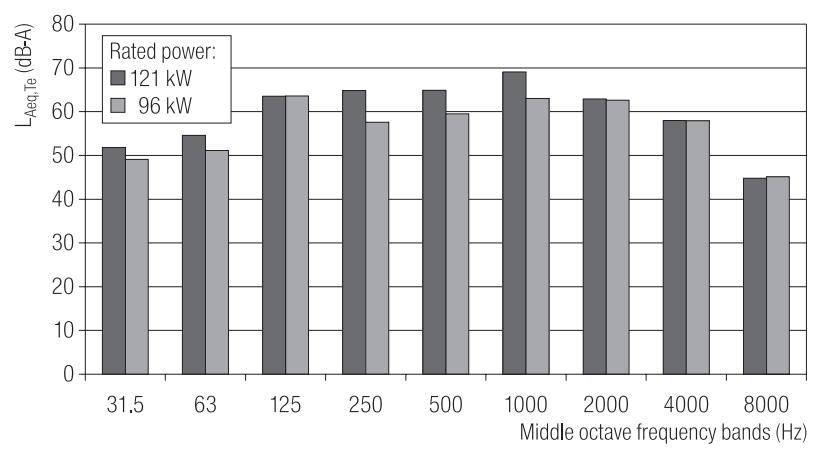

Fig. 2. Two examples of audible noise octave-band frequency spectra (fast dynamic characteristics of sound meter) inside the cabins of two modern models of agricultural tractors at a standstill and at $1500 \mathrm{rpm}$

In terms of the analysis of occupational exposure to noise in tractor cabins, the noise levels (in the case of an 8-h daily exposure) were below the maximum exposure limits for audible noise for hearing protection (Polish exposure limits $-\mathrm{L}_{\text {eq,8h }}=85 \mathrm{~dB}-\mathrm{A}, \mathrm{L}_{\text {Amax }}=115 \mathrm{~dB}-\mathrm{A}, \mathrm{L}_{\text {Cpeak }}=135 \mathrm{~dB}-\mathrm{C}$ ) [19]. Figure 1 presents the average levels of audible noise 


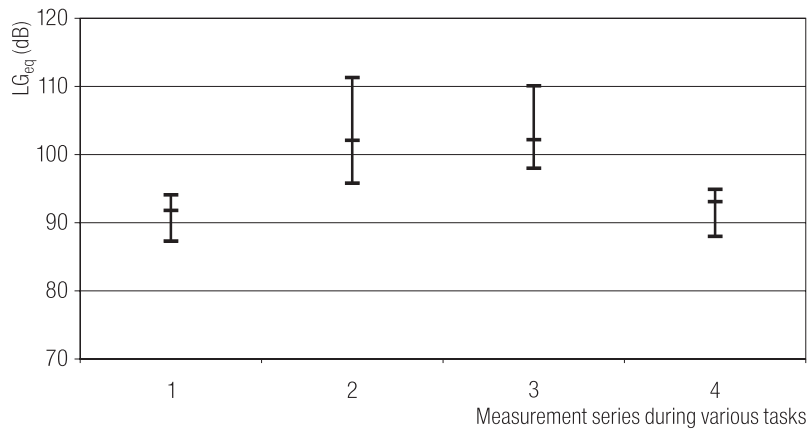

Abbreviations as in Figure 1.

Fig. 3. Task-specific infrasonic noise time averaged levels $\left(\mathrm{L}_{\mathrm{Geq}}\right)$ in the cabins of 20 selected modern tractors

inside the cabins during performance of various tasks $\left(\mathrm{L}_{\text {Aeq,Te }}\right)$ and the values of measurement uncertainty. Figure 1 presents considerable differences in the noise levels depending on the way the tractor moves and the engine load. The factors which influence noise levels include soil and weather conditions as well as the individual driver's skills. In spectrum analysis the highest noise levels occurred at frequencies of $250 \mathrm{~Hz}, 1$ and $2 \mathrm{kHz}$ (Figure 2).

Figure 3 presents average levels of infrasonic noise inside the cabins during performance of various tasks $\left(\mathrm{L}_{\mathrm{Geq}, \mathrm{Te}}\right)$. Infrasound noise levels (G-weighted) ranged from 87.3 to $111.3 \mathrm{~dB}-\mathrm{G}$ (Figure 3). The driver-experienced exposure to infrasound increased significantly along with the motion of the vehicle.

\section{DISCUSSION}

Audible noise levels occurring inside the cabin were lower than, for example, Polish Occupational Exposure Limits $\left(\mathrm{L}_{\mathrm{eq}, 8 \mathrm{~h}}=85 \mathrm{~dB}-\mathrm{A}, \mathrm{L}_{\text {Amax }}=115 \mathrm{~dB}-\mathrm{C}, \mathrm{L}_{\text {Cpeak }}=135 \mathrm{~dB}-\mathrm{C}\right)$, and were below the level of $80 \mathrm{~dB}-\mathrm{A}$ (the lower limit value for the risk of hearing loss, especially in individuals sensitive to this hazard) $[19,20]$. The noise generated by engines can be potentially hazardous to hearing only if the cabin is damaged or open. This is especially true for individuals who are sensitive to noise [20]. The so-called non-auditory effects of exposure to noise are the only adverse health effect of the measured values of exposure to audible noise which can occur. In this case, the noise can be considered as a non-specific stressor; this type of physiological reaction is triggered by a neurophysiological mechanism which relies on the activation of the brain's reticular activating system via the auditory system. Noise can, therefore, influence motor, perceptual and cognitive behaviour, and also trigger glandular, cardiovascular and gastrointestinal changes by means of the autonomic nervous system. Despite decades of research and numerous studies, relatively little can be said with much confidence [21-23]. It is important to note that noise has been found to transiently elevate diastolic and systolic pressure in volunteers exposed to $75 \mathrm{~dB}-\mathrm{A}$ noise [24]. Other potentially occurring non-auditory effects in tractor operators may include the influence of noise on fatigue and work quality (especially due to coexisting whole-body vibration) $[7,8,25,26]$, the operator's alienation from surrounding noises and conversation problems [27-31]. In the examined tractors, the highest noise levels (although of various values) were identified for the $1000-2000 \mathrm{~Hz}$ frequency range of the speaking voice (Figure 2). Additionally, the assessed noise levels can negatively influence the tasks performed by tractors operators [32].

\section{Infrasonic noise levels}

In the presented study, G-weighted sound levels were significant $[11,19]$. The effect of low frequency noise on drivers or tractor operators still requires further investigation. For example, according to the European Economic Commission Regulations, testing of external audible vehicle noise is only applied in Europe [33,34]. Exposure to infrasound of about $90 \mathrm{~dB}-\mathrm{G}$ can cause excessive fatigue, drowsiness, sluggishness, headaches, extension of reaction time, irritation, decrease of psychomotor efficiency, disrupted attention and perception, diminished sharpness and field of vision, resonance of human organs and additionally noise-induced hearing loss [12,35-41]. 


\section{CONCLUSIONS}

1. Audible noise levels have no potential to adversely affect the hearing organ during the tasks performed inside closed cabins of the modern agricultural tractors analysed in this study.

2. Due to the relatively low audible noise levels inside modern agricultural tractor cabins, non-auditory effects are the only adverse symptoms that can develop.

3. Modern agricultural tractors emit considerable infrasonic noise levels.

4. All tractors introduced into the market should be subjected to tests with regard to infrasonic noise levels.

\section{REFERENCES}

1. Solecki L. Risk of noise-induced hearing loss in farm tractor operators. Med Pr 2001;52:265-70.

2. Aybek A, Kamer HA, Arslan S. Personal noise exposures of operators of agricultural tractors. Appl Ergon 2010;41: 274-81.

3. Cieślikowski B, Ślipek Z. Methods to lower noise level in agricultural tractor cabin - selection of insulating material structures. Inż Rol 2007;94:15-20.

4. Directive 2009/63/EC of the European Parliament and of the Council of 13 July 2009 (certain parts and characteristics of wheeled agricultural or forestry tractors). Official Journal of the European Union L 214/23 from 19th August 2009.

5. Bovenzi M. Health effects of mechanical vibration. G Ital Lav Ergon 2005;27:58-64.

6. Seidel H. Selected health risks caused by long-term, whole body vibration. Am J Ind Med 1993;23:589-604.

7. Solecki L. Preliminary recognition of whole body vibration risk in private farmers' working conditions. Ann Agric Environ Med 2007;14:299-304.

8. Solecki L. Assessment of annual exposure of private farmers to whole body mechanical vibration on selected family farms of plant production profile. Ann Agric Environ Med 2010;17: 243-50.
9. Sorainen E, Penttinen J, Kallio M, Rytkonen E, Taattola K. Whole-body vibration of tractor drivers during harrowing. Am Ind Hyg Assoc J 1998;59:642-4.

10. IEC 1994:60050-801. International Electrotechnical Vocabulary - Chapter 801: Acoustics and electroacoustics. Geneva: International Electrotechnical Commission; 1994.

11. PN-Z-01338:2010. Acoustics - measurement and assessment of infrasonic noise at the workplaces. Warszawa: Polish Committee for Standardization; 2010.

12. Nowacki G, Mitraszewska I, Kamiński T, Wierzejski A. Research of infrasound noise in heavy goods vehicle and busses. The 8th International Conference „Reliability and Statistics in Transportation and Communication"; 2008 Oct 15-18; Riga, Latvia. Riga: 2008.

13. EN ISO 9612:2009. Acoustics - determination of occupational noise exposure - engineering method. Geneva: International Organization for Standardization; 2009.

14. EN ISO 9612:2009. Acoustics - determination of occupational noise exposure - engineering method. Geneva: International Organization for Standardization; 2009.

15. ISO/IEC 17025:2005. General requirements for the competence of testing and calibration laboratories. Geneva: International Organization for Standardization; 2005

16. ISO 61672:2003. Electroacoustics - sound level meters. Geneva: International Organization for Standardization; 2003.

18. ISO 7196:1995. Acoustics - Frequency-weighting characteristic for infrasound measurements. Geneva: International Organization for Standardization; 1995.

17. Report of the Working Party of Noise (GRB). United Nations, Economic and Social Council. Inland Transport Committee. World Forum for Harmonization of Vehicle Regulations; 2004 Sep 23-24 TRANS/WP.29/GRB/38 from 15th October 2004.

19. Regulation of Polish Minister for Labour and Social Policies of 29 November 2002 on High Admissible Intensities and Concentrations Levels in work environment. The Official Journal of the Poland 2002, no. 217, pos. 1833 (with changes) (DzU z 2002 r. nr 217, poz. 1833 z późn. zm.). 
20. Nowak J, Bilski B. Factors modifying noise-induced hearing loss. Med Pr 2003;53:81-6.

21. Andren L. Cardiovascular effects of noise. Acta Med Scand 1982;657:11-34.

22. Bartsch R, Bruckner C, Dieroff HG. Influence of different kinds of noise on the ear and some physiological and psychological parameters. Int Arch Occup Environ Health 1986;58:217-26.

23. Borg E. Physiological aspects of the effects of sound on man and animals. Acta Otolaryngol 1979;360:80-5.

24. Petiot JC, Parrot J, Lobreau JP, Smolik HJ. Cardiovascular effects of impulse noise, road traffic noise and intermittent pink noise at $L A e q=75 \mathrm{~dB}$, as a function of sex, age and level of anxiety: A comparative study. Int Arch Occup Environ Health 1992;63:485-93.

25. Ljungberg JK, Neely G. Cognitive after-effects of vibration and noise exposure and the role of subjective noise sensitivity. J Occup Health 2007;49:111-6.

26. Ljungberg J, Neely G, Lundström R. Cognitive performance and subjective experience during combined exposures to whole-body vibration and noise. Ann Arch Occup Environ Health 2004;77:217-21.

27. Tremblay C, Picard M, Barbarosie T, Banville R. Clinical study of speech understanding in noise. Audiology 1991;30:212-40.

28. Suter AH. Communication and job performance in noise: A review. ASHA Monogr 1992;28:1-84.

29. Pearsons KS. Effect of tone/noise combination on speech intelligibility. J Acoust Soc Am 1977;61:884-6.

30. PN-N-1307:1994. Noise - permissible values of noise in the workplace - requirements relating to measurements. Warszawa: Polish Committee for Standardization; 1994.

31. Cox RM, Moore JN. Composite speech spectrum for hearing and gain prescriptions. J Speech Hear Res 1988;31:102-7.

32. Karimi D, Mondor TA, Mann DD. Application of auditory signals to the operation of an agricultural vehicle: Results of pilot testing. J Agric Saf Health 2008;14:71-8.
33. Commission Directive 2007/34/EC of 14 June 2007 amending, for the purposes of its adaptation to technical progress, Council Directive 70/157/EEC concerning the permissible sound level and the exhaust system of motor vehicles. Off J EU L 155.49 (Jun 15, 2007).

34. Council Directive 70/157/EEC of 6 February 1970 on the approximation of the laws of the Member States relating to the permissible sound level and the exhaust system of motor vehicles. Off J EU L 70.42.16, (Feb 23, 1970).

35. Benton S., Leventhall H.G. Experiments into the impact of low level, low frequency noise upon human behaviour. J Low Freq Noise Vibr 1886;5:143-62.

36. Landström, U, Lindblom-Häggqvist S, Löfstedt P. Low frequency noise in Lorries and correlated effects on drivers. J Low Freq Noise Vibr 1988;7:104-9.

37. Landström U, Lundström R, Byström M. Exposure to infrasound perception and changes in wakefulness. J Low Freq Noise Vibr 1983;2:1-11.

38. Sandberg U. Combined effects of noise, infrasound and vibration on driver performance. International Conference on Noise Control Engineering (Inter-Noise 83) in Edinburgh, Great Britain 13-15th July 1983. Conference materials. Proc Internoise 1983;12:887-90.

39. Sandberg U. Identification of infrasound generation mechanisms in a bus. Proceedings of the 4th International Meeting on Low Frequency Noise and Vibration; 9-11th June 1987; Umea, Sweden. Umea: Umea University; 1987.

40. Fairley TE. Predicting the discomfort caused by tractor vibration. Ergonomics 1995;38:2091-106.

41. Futatsuka M, Maeda S, Inaoka T, Nagano M, Shono M, Miyakita T. Whole-body vibration and health effects in the agricultural machinery drivers. Ind Health 1998;36:127-32.

This work is available in Open Access model and licensed under a Creative Commons Attribution-NonCommercial 3.0 Poland License - http://creativecommons.org/ licenses/by-nc/3.0/pl/deed.en. 